Portland State University

PDXScholar

\title{
A Self-Referencing Non-Destructive Test Method to Detect Damage in Reinforced Concrete Bridge Decks Using Nonlinear Vibration Response Characteristics
}

Ali Hafiz

Portland State University, hafiz@pdx.edu

Thomas Schumacher

Portland State University, thomas.schumacher@pdx.edu

Anis M. Raad

Valar Consulting Engineering

Follow this and additional works at: https://pdxscholar.library.pdx.edu/cengin_fac

Part of the Civil and Environmental Engineering Commons

Let us know how access to this document benefits you.

\section{Citation Details}

Published as: Hafiz, A., Schumacher, T., \& Raad, A. (2022). A self-referencing non-destructive test method to detect damage in reinforced concrete bridge decks using nonlinear vibration response characteristics. Construction and Building Materials, 318, 125924.

This Pre-Print is brought to you for free and open access. It has been accepted for inclusion in Civil and Environmental Engineering Faculty Publications and Presentations by an authorized administrator of PDXScholar. Please contact us if we can make this document more accessible: pdxscholar@pdx.edu. 


\section{A Self-Referencing Non-Destructive Test Method to Detect Damage \\ 2 \\ in Reinforced Concrete Bridge Decks Using Nonlinear Vibration \\ Response Characteristics}

\author{
Ali Hafiz ${ }^{1}$, Thomas Schumacher ${ }^{2, *}$, and Anis Raad ${ }^{3}$
}

${ }^{1} \mathrm{PhD}$, Senior Engineer, Advanced Infrastructure Design, Inc., Hamilton, NJ, E-mail: ahafiz@aidpe.com

${ }^{2}$ PhD, PE (DE), Associate Professor, Civil and Environmental Engineering, Portland State University, Portland, OR, E-mail: thomas.schumacher@pdx.edu

${ }^{3}$ M.S., EIT Engineer, VALAR Consulting Engineering LLC, Clackamas, OR, E-mail: anis.raad@valarengineering.com

${ }^{*}$ Corresponding Author 
22 deck, varying the impact force applied to a specific test point does not affect the corresponding

23 frequency response function (FRF) for frequencies that lie within the measurement system's linear

24 operating range. On the other hand, the FRFs for a test point that contains damage changes when

25 the impact force is increased, indicating a nonlinear vibration response. To demonstrate that the 26 concept works theoretically, two 2D finite element (FE) models of a bridge deck, one containing

27 a shallow delamination, were developed and their responses to impact forces of increasing 28 amplitude compared. IR data from an in-service bridge deck was processed and analyzed. Visual 29 inspection results and ultra-high-pressure hydro-blasting performed on the deck for rehabilitation 30 purposes provided an opportunity to compare the obtained results with common inspection 31 methods and actual damage extent. Based on the observations, a new damage index, referred to as 32 nonlinear vibration index (NVI), is proposed and shown to be sensitive to damage, including 33 shallow delaminations that were missed by means of visual inspection.

35 Keyword: Bridge deck; reinforced concrete; damage detection; delamination; condition 36 assessment; non-destructive testing; impulse response testing; nonlinear vibration characteristics;

37 frequency response function; finite element model.

\section{Background and Motivation}

40 Highway infrastructure in the United States and around the world experience degradation due to

41 environmental conditions and increasing traffic volume. Additionally, damage is caused by

42 degradation of structural materials due to aging. The corrosion of steel bars and resulting gradual

43 degradation of the concrete are the most common causes of damage in reinforced concrete 
44 structures (NCHRP 2004). Accordingly, bridge engineers are typically concerned about four

45 primary damage mechanisms: steel reinforcing bar (or rebar) corrosion, delamination, vertical

46 cracks, and concrete degradation (Gucunski, Imani et al. 2013). Delaminations in concrete bridge

47 decks, which are the focus of this article, are an advanced form of damage in reinforced concrete

48 bridge decks resulting from advanced corrosion of the embedded steel rebar, and are initiated by

49 the presence of cracks in the concrete and sufficient moisture. The rebars expand due to corrosion,

50 leading to cracking and subsurface fracture planes within the concrete. With advancing corrosion,

51 delaminations can progress to open spalls.

53 To date, many non-destructive test (NDT) methods have been developed to detect deterioration in

54 concrete bridge decks such as delaminations (Scott, Rezaizadeh et al. 2003, Arndt, Schumacher et

55 al. 2011, Zhang, Harichandran et al. 2012, Gucunski, Imani et al. 2013, Sun, Zhu et al. 2018,

56 Garrett 2019). An ultrasonic stress pulse is used in techniques aiming to initiate high-frequency

57 stress waves, which include impact echo (IE) and ultrasonic echo (UE) testing (Sansalone and

58 Streett 1997, Kee, Oh et al. 2012, Zhang, Harichandran et al. 2012, Shokouhi, Wolf et al. 2014,

59 Scherr and Grosse 2021). On the other hand, low-frequency dynamic response characteristics are

60 used in impulse response (IR) testing (Davis 2003). In the latter method, specific characteristics of

61 the dynamic response to a given hammer impact are evaluated to detect delaminations among other

62 degradations. IR testing is based on a hammer impact resulting in a low strain stress wave and

63 vibrations and it has been primarily used for pile integrity testing (Davis and Robertson 1975).

64 While the methodology of this test has not changed since its popularization in the 1970s,

65 application to other types of concrete members has increased notably (Davis 2003, Davis and

66 Germann Petersen 2003, Sajid and Chouinard 2019). ASTM Standard C1740 provides guidance 
67 for evaluating the condition of concrete plates such as bridge decks using the IR method (ASTM

68 2016). In IR testing, an instrumented hammer is struck against the concrete surface to generate

69 local vibrations, and the dynamic response is measured at a nearby location using a geophone or

70 accelerometer. The frequency response function (FRF) is obtained by dividing the dynamic

71 response by the impact force, where both signals are expressed in the frequency domain. The

72 typical frequency range used to evaluate the condition of a concrete slab is 0 to $1 \mathrm{kHz}$ (ASTM

73 2016). Several parameters are computed from the FRF, referred to as mobility plot, that are used

74 as empirical indicators of damage. For concrete bridge deck condition assessment, all available

75 NDT technologies have limitations to identify certain types of defects (Abdelkhalek and Zayed

76 2020). One of the limitations of the IR method is that it cannot detect defects with a large depth-

77 to-size ratio (Lin, Azari et al. 2021). Moreover, limitations in detecting delaminations of a certain

78 size appear to be related to the fixed frequency limit prescribed by the ASTM standard (Clem,

79 Popovics et al. 2013). Finally, the method may not be sensitive to early stages of damage because

80 it solely relies on linear response characteristics.

82 In structural dynamics, modal analysis is the most popular approach for performing linear-elastic

83 structural system identification, where the modal parameters, i.e., natural vibration frequencies,

84 mode shapes, and damping ratio, can be extracted and monitored over time (Kerschen, Worden et

85 al. 2006, Farrar and Worden 2013). Since these parameters are a function of the structural and

86 material properties, they can be related to the initiation and propagation of damage (Doebling,

87 Farrar et al. 1998). Samman and Biswas (Samman and Biswas 1994, Samman and Biswas 1994)

88 presented waveform-recognition techniques to detect damage in bridges and they applied these

89 techniques under both laboratory and real-world conditions by detecting damage in a laboratory- 
90 sized bridge and a highway bridge. These techniques depend on a comparison between two

91 dynamic signatures: one from an intact (= reference) state and the other from a state with a certain

92 level of damage. Zhou et al. (Zhou, Wegner et al. 2007) utilized vibration-based damage detection

93 (VBDD) methods to detect and localize low levels of damage in the deck of a two-girder, simply-

94 supported bridge. They conducted their study using laboratory-based experimental and finite

95 element analysis. The methods evaluated included the mode shape curvature method, the change

96 in flexibility method, the damage index method, the change in uniform flexibility curvature

97 method, and the change in mode shape method. They concluded that VBDD methods have

98 excellent potential as structural health-monitoring tools for bridge decks. However, these methods

99 require extracting the mode shapes, a process requiring multiple sensors. Additionally, there is

100 difficulty in extracting the mode shapes for bride decks in the field (Salawu and Williams 1995,

101 Bien, Krzyzanowski et al. 2002) because the excitation forces are required to have sufficiently

102 large amplitudes (Bien, Krzyzanowski et al. 2002). Kee et al. (Kee and Gucunski 2016) used

103 impact-echo (IE) testing in order to improve the interpretation of local flexural vibration modes of

104 delaminated areas in concrete bridge decks. This approach was more accurate than conventional

105 binary images for detecting the areal sizes of shallow delaminations. On the other hand, for deep

106 delaminations, the conventional IE approach was more accurate (Kee and Gucunski 2016). Finally,

107 there are two challenges in using modal analysis methods for damage detection: first, it requires

108 the dynamic response for the reference case, which is unavailable in most cases. Second,

109 temperature variations can have a significant effect on the frequency response of the structure

110 (Zhou, Ni et al. 2011), and there might be significant difficulty in distinguishing between the

111 effects of temperature and damage. 
112 Fundamentally, if a structural system fails to follow the principle of superposition, i.e., its response

113 deviates from linearity, then it can be considered nonlinear (Ewins 1995), and traditional linear-

114 elastic modal analysis cannot be used to analyze the dynamic response. In reality, most structural

115 systems exhibit a certain level of nonlinear behavior (Lin 1990). The sources of nonlinearity can

116 be summarized as (Farrar and Worden 2013): (1) Geometric nonlinearity, when the structure

117 exhibits large displacements, (2) material nonlinearity, when a material exhibits a nonlinear stress-

118 strain response, (3) nonlinear boundary conditions, where imperfect boundary conditions result in

119 a nonlinear vibration response, (4) damage, for example cracking, and (5) energy dissipation due

120 to damping. This last phenomenon is to date not fully understood. According to Samman and

121 Biswas (Samman and Biswas 1994), the identification of nonlinear behavior of a structural system

122 includes three steps. The first step is "Detection," where the existence of nonlinearity in structural

123 behavior is determined. "Characterization" is the second step, where the source and location of the

124 nonlinearity is investigated, and its behavior established. The final step is "Parameter estimation."

125 In this step, the coefficients of the nonlinearity are estimated, and their uncertainty quantified.

126 There are many identification methods that have been established in the preceding three decades,

127 such as the restoring force surface method and nonlinear autoregressive moving average model

128 with exogenous inputs (NARMAX) method (Kerschen, Worden et al. 2006, Noel and Kerschen

129 2017). Nonlinearity is important in damage detection for cases where damage changes the behavior

130 of the structural form (initially) from linear to nonlinear (Lin 1990). Underwood et al. (Underwood,

131 Meyer et al. 2015) investigated using nonlinear behavior for detecting and locating subsurface

132 damage in composite materials by comparing the FRFs for different input force amplitudes. Idriss

133 et al. (Idriss, El Mahi et al. 2015) found that nonlinear vibration parameters are much more

134 sensitive to debonding damage in sandwich beams than linear vibration parameters. Zhao et al. 
135 (Zhao, Lang et al. 2015) presented a new transmissibility analysis method for the detection and

136 location of damage using the characteristics of nonlinear vibrations of structural multi-degree-of-

137 freedom (MDF) systems.

138

139 This literature review reveals an opportunity to improve the sensitivity of the established IR test

140 method to detect delaminations in concrete bridge decks early on. The objective of this study was

141 thus to develop and evaluate a highly sensitive yet simple NDT test method to detect damage such

142 as delaminations in reinforced concrete bridge decks. Unlike traditional vibration-based methods,

143 the method discussed herein is self-referencing, i.e., it does not require a reference measurement

144 of the undamaged state for comparison. Using the impulse response (IR) test procedure, the

145 collected data is analyzed in a manner that enables us to detect damage based on deviation from

146 linearity, following what was originally proposed by Ewins (Ewins 1995), i.e., by comparing the

147 frequency response functions (FRF) due to impacts of varying amplitude. The significance of the

148 proposed method lies in its availability, simplicity, cost-effectiveness, and that its application could

149 be extended to other members.

151 2. Test Methodology

152 The proposed method is based on the vibration response of a reinforced concrete bridge deck and 153 produces a nonlinear vibration index $(N V I)$ for each test point on the member. The same 154 instruments and general test procedure used for impulse response (IR) testing and vibration-based 155 methods apply: An instrumented hammer is used to create an impact at a specific test point and 156 the vibration response at a nearby location is measured with an accelerometer (see Fig. 1). The 
157 proposed method requires applying at least two impact forces with different amplitudes for each

158 test point and measuring their vibration responses separately. The basic concept is that for a test

159 point on an ideal undamaged linear-elastic structural system, varying the amplitude of the impact

160 force does not result in a change in the FRF. On the other hand, a test point on a system that

161 contains damage exhibits nonlinear characteristics, which result in different FRFs for impact forces

162 of different amplitude. The frequency ranges of the FRFs need to be within the linear operating

163 range of the measurement system.

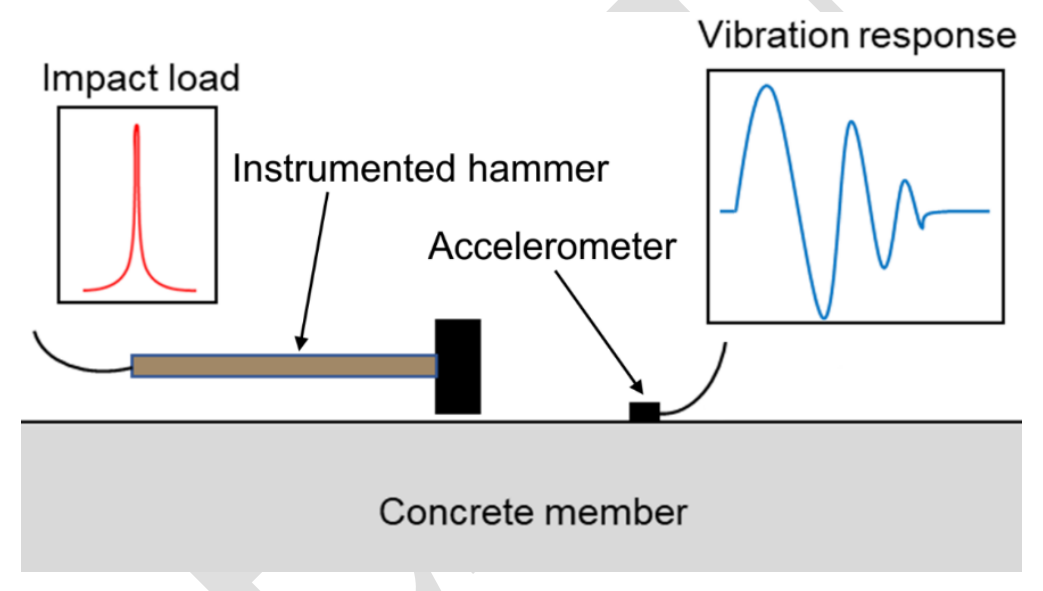

Fig. 1. Illustration of test setup used in this study.

168 A parameter describing the nonlinearity effect, or deviation from linearity, can be computed in

169 multiple ways, see e.g., Idriss et al. (Idriss, El Mahi et al. 2015), Zhao et al. (Zhao, Lang et al.

170 2015) and Liu et al. (Liu, Todd et al. 2017). Typically, the correlation coefficient or root mean

171 square are used. Assuming two different impact forces (e.g., soft and strong), our proposed NVI is

172 computed for each test point as follows: 


$$
F R F=H(f)=\frac{Y(f)}{X(f)}=\frac{G_{x y}(f)}{G_{x x}(f)}
$$

$$
\rho_{H_{0}, H_{i}}(f)=\rho(f)=\frac{\operatorname{COV}\left(H_{0}, H_{i}\right)(f)}{\sigma_{H_{0}} \sigma_{H_{i}}}=\frac{\sigma_{H_{0}, H_{i}}}{\sigma_{H_{0}} \sigma_{H_{i}}}
$$

$$
R^{2}(f)=\rho(f)^{2}
$$

$$
N V I=\frac{\sum_{f_{1}}^{f_{2}} R^{2}(f)}{f_{2}-f_{1}}
$$

where $Y(f)$ and $X(f)$ are the frequency domain representations of the measured vibration response

180 and the impact force, respectively, and $H_{0}$ and $H_{i}$ are the FRFs associated with two impact forces

181 having different amplitudes. In this study, the FRF associated with the lowest force of a set of

182 measurements from a particular test point was assigned to $H_{0}$, representing the reference case.

$183 \operatorname{COV}\left(H_{0}, H_{i}\right)$ is the covariance between $H_{0}$ and $H_{i}$, and $\mu$ indicates mean values. $\rho$ is the correlation

184 coefficient, $f_{1}$ and $f_{2}$ are the lower and upper limits of a selected frequency range, respectively. $G_{x y}$

185 is the cross spectrum between the measured vibration response and the impact force and $G_{x x}$ is the

186 auto spectrum of the measured impact force. $N V I$ is the proposed nonlinear vibration index and a

187 scalar between 0 and 1 , indicating the level of nonlinearity in the structural system under

188 evaluation. When $H_{0}=H_{i}$, then $N V I=1$, implying the structural system behaves linearly;

189 otherwise, the FRFs are different, which implies that the structural system exhibits a certain level 190 of nonlinearity. 
192 In our proposed method, a test point on a bridge deck without damage is assumed to represent an

193 ideal linear-elastic structural system, i.e., the FRF does not change with an increase in the

194 amplitude of the impact force. This is illustrated in Fig. 2, where the FRFs of four impact forces

195 with increasing amplitude [Fig. 2 (a)] are shown for test point A1 [see Fig. 9 (a)] on the tested

196 bridge deck (introduced in Section 5.1). From Fig. 2 (b), it can be observed that increasing the

197 applied impact force, even doubling it, does not result in significant visible differences between

198 the FRFs, indicating system linearity, which in turn implies that no damage is present in the system.

199 Our hypothesis is that if any area of a bridge deck deviates from linearity, some type and level

200 damage can be assumed to be present. The observed nonlinearity is assumed to be caused by

201 cracking and crack boundary interaction. Note that all other potential sources of nonlinearity must

202 be controlled, i.e., minimized (see Section 5.3). Also, the selected frequency range ( $f_{1}=225$ to $f_{2}$

$203=500 \mathrm{~Hz}$ ) was determined by trial and error and is application dependent. More details are 204 provided in Section 5.2.

205
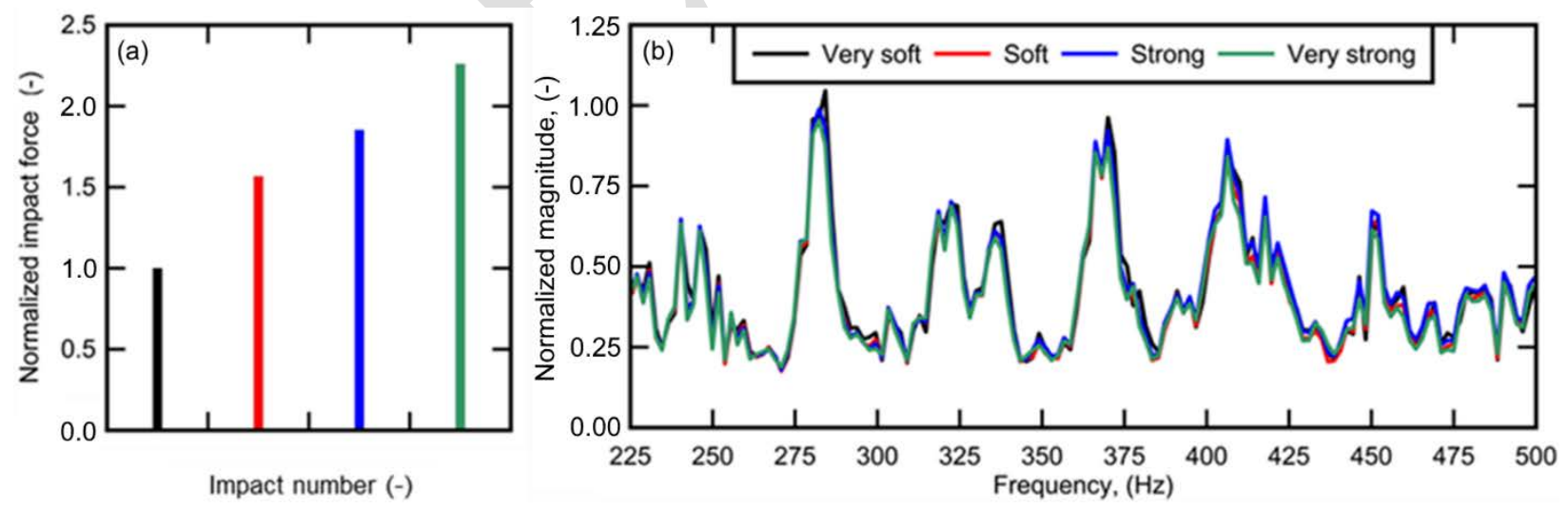

Fig. 2. Sample FRFs for test point A1 [see Fig. 9 (a)] on the selected bridge deck. 
209 Fig. 3 shows a sample of the coefficient of determination, $R^{2}$ as a function of frequency. This

210 coefficient was determined by comparing the FRFs of the very soft and very strong impact forces

211 shown in Fig. 2 (b). Finally, the normalized area under the coefficient of determination-frequency

212 curve represents the $N V I$, which for this case is 0.98 . This value confirms that the system shows a

213 very high degree of linearity at this test point, which was consistent with visual inspection results.

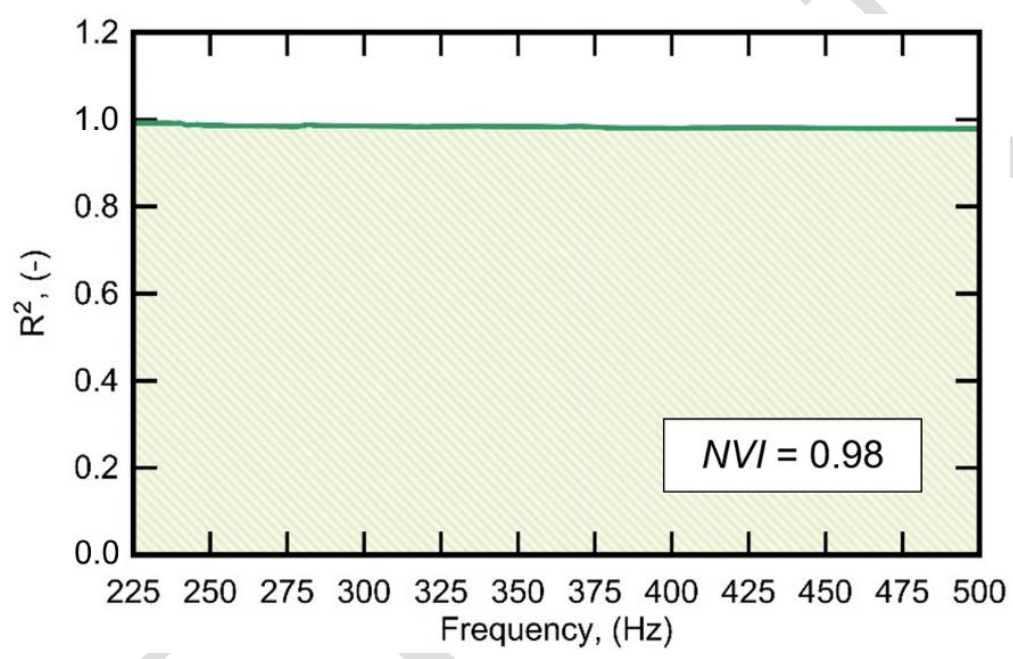

216 Fig. 3. Sample $R^{2}$-frequency relationship for two FRFs [very soft and very strong from test point

A1, see Fig. 9 (a)] vs. frequency and corresponding $N V I$.

219 Unless otherwise noted, computations were performed in MATLAB (Mathworks 2020) and plots

220 generated in DPlot (Hyde 2014). Regressions and statistical metrics were computed using

221 STATGRAPHICS (Centurion 2020). 


\section{3. Numerical Study}

\section{3.1. Modeling}

224 A plane strain 2D finite element (FE) model was created to simulate the dynamic response of 225 concrete bridge decks with and without delamination theoretically. The objective was to study the 226 effect of a delamination on the dynamic response and whether it causes a nonlinear response. To 227 that end, depth and width of the delamination were selected based on trial and error to prove that 228 the idea works and not necessarily to represent an actual scenario. The bridge deck was modeled 229 as a simply-supported 2D beam using ABAQUS (Systemes 2012) and guided by previous work 230 reported in (Clem, Popovics et al. 2013). The model was created using quadrilateral elements, as 231 shown in Fig. 4. The span length is $1.00 \mathrm{~m}$ (39.4 in) and the depth is $240 \mathrm{~mm}$ (9.45 in). The material 232 properties assigned to the deck are normal-weight concrete with a modulus of elasticity, $E_{c}$, 233 23,520 MPa (3,410 ksi) and a mass density, $\rho=2400 \mathrm{~kg} / \mathrm{m}^{3}\left(150 \mathrm{lb} / \mathrm{ft}^{3}\right)$. An impact force modeled 234 after a typical one observed in the field measurements (see Section 5) was applied as a distributed 235 time-varying force over a length of $40 \mathrm{~mm}$ (1.58 in), which corresponds to the diameter of the 236 hammer tip. The forcing function followed a sine (half of a complete cycle) with a duration of 1.8 237 ms. The acceleration response was measured at a point located $45 \mathrm{~mm}$ (1.77 in) from the applied 238 impact force.

240 Two separate beam models were created: Model 1 refers to the concrete beam without 241 delaminations, i.e., the intact (or reference) beam. Model 2 has the same geometry as Model 1

242 beam but with a delamination, which was modeled as a gap with the following dimensions: Width $243=0.5 \mathrm{~mm}(0.02 \mathrm{in})$, length $=800 \mathrm{~mm}$ (31.5 in), located about the center of the beam at a depth of $24415 \mathrm{~mm}$ (0.59 in) (see Fig. 4). To capture interactions of the delamination boundaries during 
245 vibration, these surfaces were modeled as contact elements. In both models, eight impact forces

246 were applied to each of the beams where the peak value of the impact force varied from 0.5 to 15

$247 \mathrm{kN}$ (0.112 to $3.37 \mathrm{kip}$ ). This range was selected based on the actual forces employed in the field

248 (see Section 5). Note that impact forces reported herein are total force and equivalent distributed

249 forces as applied to the FE models can be calculated as force/0.04 m. A dynamic explicit step

250 routine with a time step of $10 \mu$ s and a total simulation time of $1 \mathrm{~s}$ was used. The dynamic response

251 of all 16 simulations was analyzed and is discussed in the following subsection.

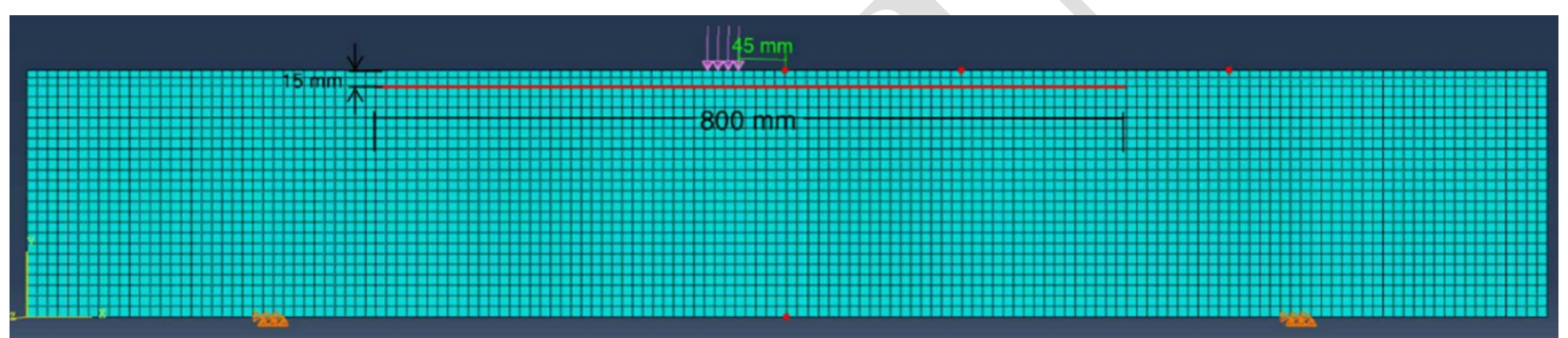

254 Fig. 4. Illustration of the 2D finite element (FE) model for Model 2. The red line indicates the

255 delamination (gap). The red point at the surface indicates the acceleration measurement point.

256 The purple arrows indicate the distributed force applied on the deck.

258 3.2. Results and Discussion

259 Fig. 5 shows the FRFs of the simulated beams with and without delamination, i.e., Model 2 and

260 Model 1, respectively, due to an impact force with an amplitude of $4 \mathrm{kN}$ (0.9 kip). While it is 261 expected that the natural frequencies of the beam change because of the delamination, the 262 interpretation of the results is not straight forward. As can be seen in Fig. 5, the FRFs look very 263 different for the two models. Not only is there no consistent shift between individual peaks, they 
264 also do not have corresponding matches, and exhibit notable differences in their half-power 265 bandwidths. The latter implies higher inherent damping in the system. In conclusion, a 266 delamination has a significant effect on the measured vibration response. However, because the 267 proposed method is self-referencing, this is not relevant.

268

269

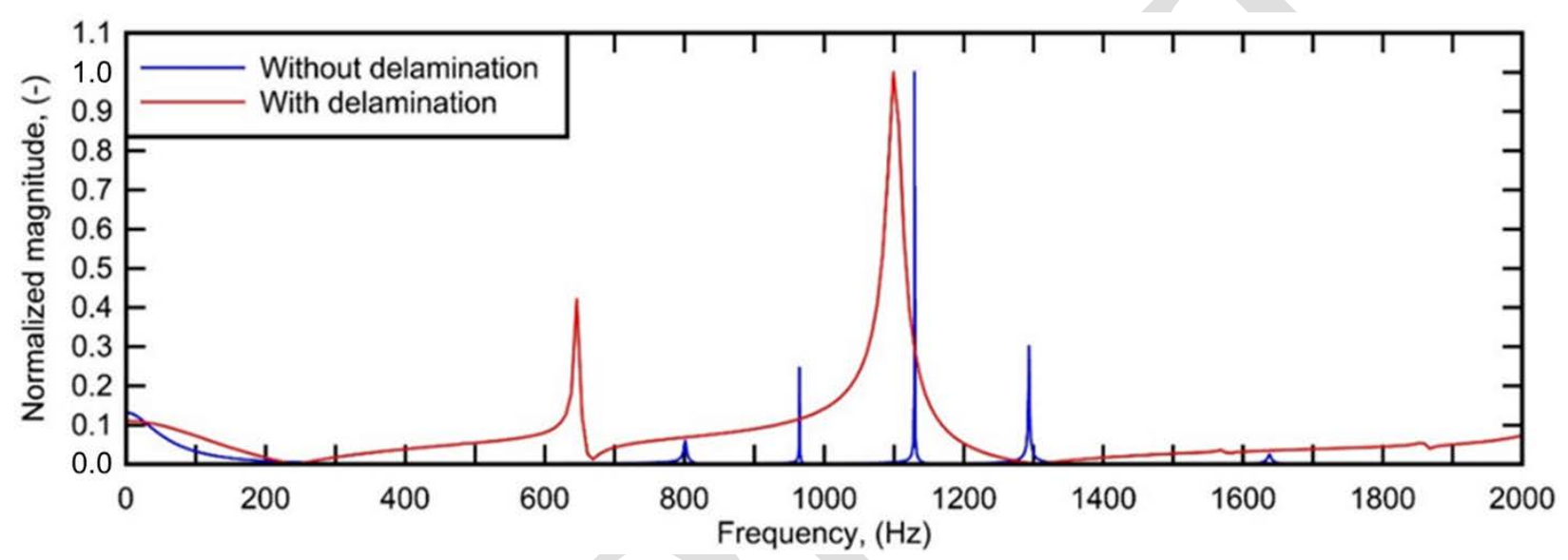

270 Fig. 5. Two sample FRFs for deck models with and without delamination; amplitude of impact force $=4 \mathrm{kN}$ (0.9 kip).

273 As can be observed in Fig. 6 (a), the FRF response of the beam model without delamination for a

274 select peak does not change due to an increasing impact force with amplitudes ranging from 0.5 to

$27515 \mathrm{kN}$ (0.11 to $3.37 \mathrm{kip}$ ). On the other hand, increasing the value of the impact force does cause

276 notable changes in the FRFs of the beam model with a delamination. This effect manifests as a

277 change in the magnitude of the selected FRF peaks where the magnitude decreases with increasing 278 impact force, as can be observed in Fig. 6 (b). 

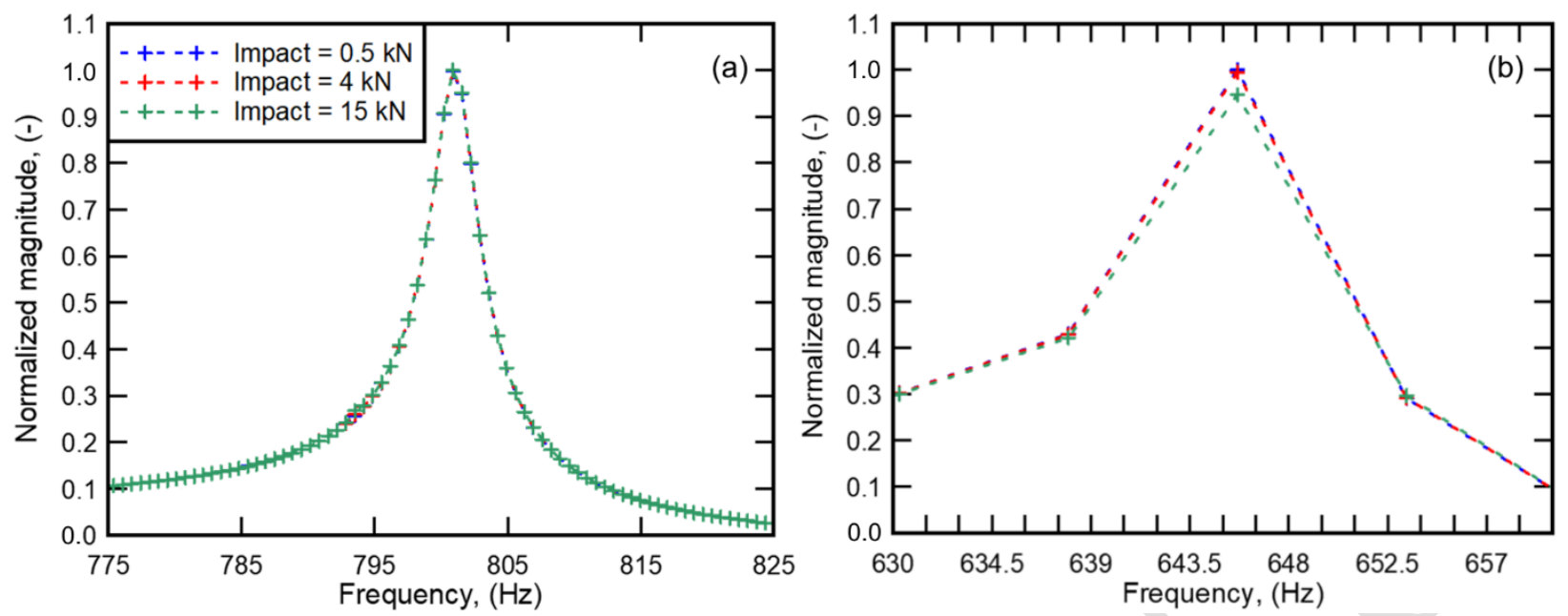

280 Fig. 6. Three sample FRF peaks (first peak) for impact forces with amplitudes, 0.5, 4 and $15 \mathrm{kN}$

281 (0.112, 0.9, and 3.37 kip): (a) Model 1 (without delamination, reference) and (b) Model 2 (with delamination).

Fig. 7 shows a comparison of the FRF peak ratios, which corresponds to the FRF peak value normalized with the FRF peak value for the smallest impact force of $0.5 \mathrm{kN}$ (0.112 kip), for both beam models. For Model 1 (reference case), it can be observed that there is a minute increase in the peak response, which can likely be attributed to the nonlinear material response of concrete

288 (see Section 4.3 for further discussion). Model 2 (delamination case), however, shows a clear 289 decrease in the peak response after the force exceeds approximately $3 \mathrm{kN}$ (0.674 kip). This 290 behavior can be associated with contact interaction of the lower and upper boundaries of the 291 simulated delamination when the vibration amplitude of these boundaries exceeds the width of the 292 delamination. Our numerical simulations show that changes of the FRF are sensitive to the 293 presence of a delamination. It can be speculated that other types of damage and degradation have 294 a similar but smaller effect. 


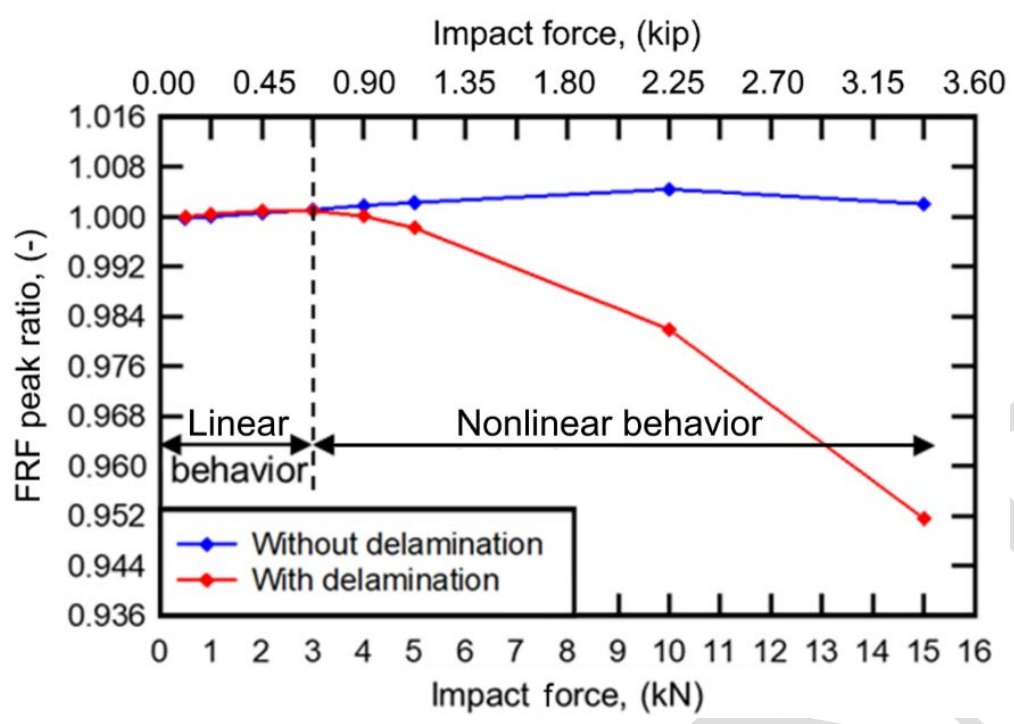

Fig. 7. FRF peak ratio vs. peak impact force value for the two FE models.

\section{Experimental Study}

\subsection{Description of Structure Used for Evaluation}

300 A steel-concrete composite bridge located in Branchport, NJ, USA was selected to evaluate the

301 proposed method's ability to detect damaged areas in an in-service reinforced concrete bridge

302 deck. The bridge, presented in Fig. 8, has a total length of $65.8 \mathrm{~m} \mathrm{(216} \mathrm{ft)}$ and is $11.3 \mathrm{~m} \mathrm{(37 \textrm {ft } )}$

303 wide. The superstructure consists of six $11.0 \mathrm{~m}$ (36 ft) long two-span sections with steel girders

304 carrying a 216 to 305 mm (8.5 to 12 in) thick reinforced concrete deck, as shown in Fig. 8 (c). Due

305 to the harsh environment combined with exposure to chlorides from seawater and deicers, the

306 bridge exhibited severe distress when it was visually inspected in July 2011. Five of the six deck

307 sections were found to have severe surface damage, showing visible signs of spalling, potholes,

308 and in some locations the steel rebars were exposed. The deck selected for this study (\#2,

309 highlighted in Figs. 8 (a) and b) showed no visual distress and hammer sounding revealed only

310 two small areas potentially having delaminations [see Fig. 9 (a)]. 

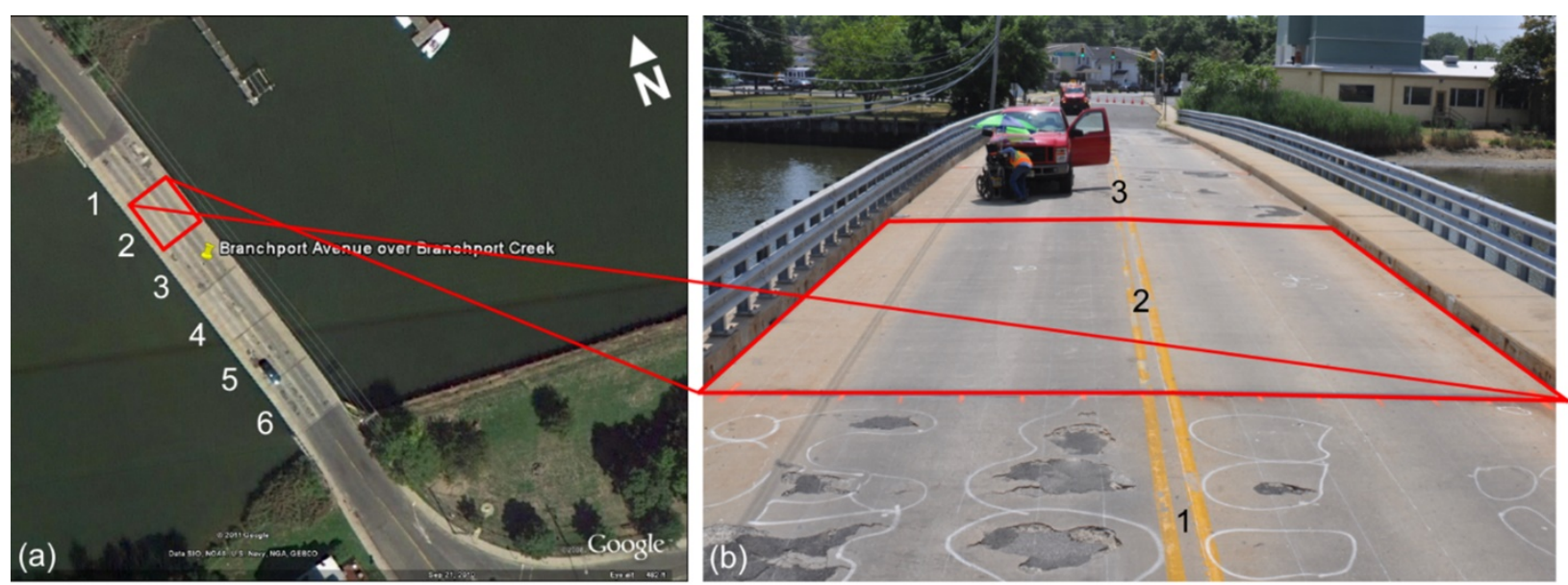

(c)

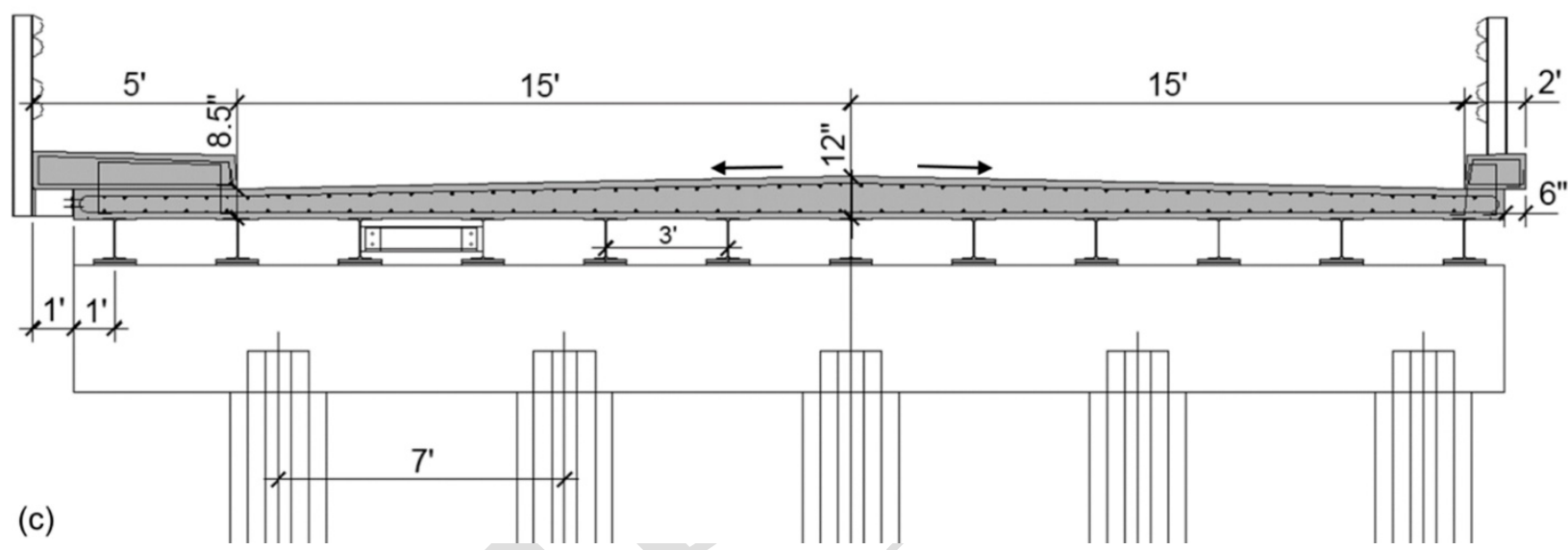

312 Fig. 8. Branchport Avenue Bridge in Long Branch, NJ: (a) Google map image showing plan view and selected deck (\#2) used as part of this study, (b) photo of Deck \#2 from a driver’s

317 Since the responsible County had planned to rehabilitate the entire bridge deck, this represented

318 an opportunity to evaluate a variety of NDT methods by comparing their results with the removed

319 concrete. Findings are reported in Clem (Clem 2013) and Celaya et al. (Celaya, Schumacher et al.

320 2014). The NDT surveys, including the IR testing discussed in this article, were completed in July

321 2011; hydro-blasting to remove surface as well as damaged concrete was performed in March 
322 2013. Before new concrete was placed in July 2013, the depth of the removed concrete was

323 measured on a 610 x $610 \mathrm{~mm}(2 \times 2 \mathrm{ft})$ grid. Depth measurements were established using traditional

324 surveying equipment and made available by Cherry, Weber \& Associates.

326 4.2. Test Setup and Procedure

327 A typical impulse response (IR) test setup was used, as illustrated in Fig. 1. The hammer (PCB,

328 Model 086D20) weighs $0.67 \mathrm{~kg}(1.5 \mathrm{lb})$ and has a $51 \mathrm{~mm}(2 \mathrm{in})$ diameter hard-plastic hammer tip

329 [ $\pm 22.2 \mathrm{kN}-$ peak (5000 lb-peak)]. It is equipped with a piezoelectric load cell connected to a signal

330 amplifier/conditioner to measure the generated impact force. The vibration response was measured

331 using a capacitive MEMS accelerometer (Silicon Designs-Model-2260-010) that has a flat frequency

332 response within $3 \mathrm{~dB}$ over the range of 0 to $1 \mathrm{kHz}$. Both input (force) and output (acceleration)

333 signals were recorded using a high-speed transient recorder (Elsys, Model TraNET 204s) with a

334 sampling frequency of $500 \mathrm{kHz}$.

336 The two-lane traffic portion of Deck \#2, measuring 9.14 x $11.0 \mathrm{~m}(30$ x $36 \mathrm{ft})$, was divided into a

$337610 \times 610 \mathrm{~mm}(2 \times 2 \mathrm{ft})$ test grid, resulting in 270 individual test points, as shown in Fig. 9 (a).

338 Two locations were selected for concrete coring and are highlighted by solid black circles. Four

339 hammer impacts were applied at each test point manually, i.e., by a human operator, with increasing

340 amplitude, referred to as "very soft", "soft", "strong”, and "very strong”, as illustrated in Fig. 9 (b).

341 Sample results from the proposed test method are shown as colored circles and marked A1, A2, B1,

342 B2, C1, C2 [see Fig. 9 (a)] and are discussed in detail in Section 6.1. 

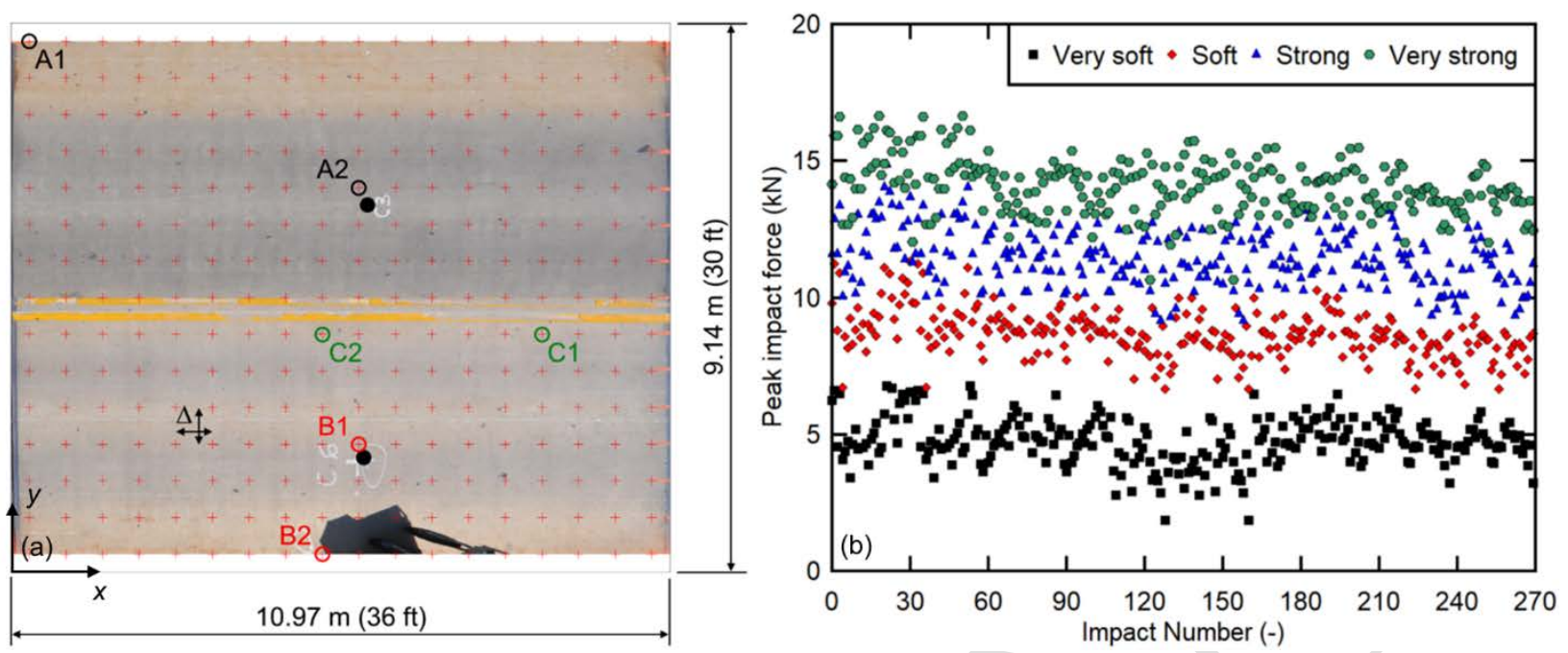

344 Fig. 9. (a) Plan view photo of Deck \#2 with test grid (red ‘+’), $\Delta=0.61 \mathrm{~m}$ (2 ft), locations of 345 sample test points A1, A2, B1, B2, C1, and C2, and extracted concrete cores (full black circles).

(b) Peak impact forces for all 270 test points. Unit conversion: $20 \mathrm{kN}=4.5 \mathrm{kip}$.

348 Fig. 10 shows sample time histories of four impact forces with different levels of amplitude and

349 the corresponding acceleration responses for one select test point. 

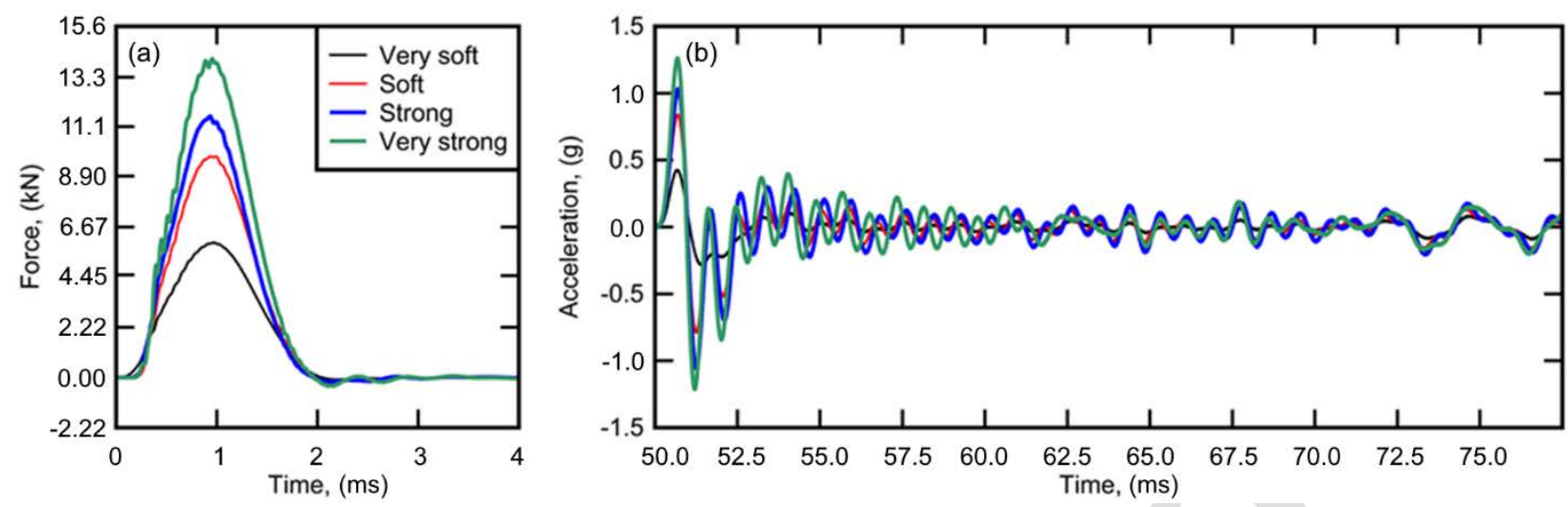

Fig. 10. Samples of (a) four impact forces and (b) corresponding acceleration responses for one select test point. Unit conversion: $15.6 \mathrm{kN}=3.5 \mathrm{kip}$.

\subsection{Sources of Nonlinearity}

Structural systems may exhibit nonlinear vibrations due to several factors (Farrar and Worden 2013). For the system investigated in this study, two factors are considered: Material nonlinearity and crack boundary interaction. The former is due to the nonlinear stress-strain relationship of concrete. To ensure that our proposed NVI is not affected by this nonlinearity, the stresses generated from the impact forces were calculated and compared with the theoretical concrete stress-strain relationship proposed by Carreira and Chu (Carreira and Chu 1985). Fig. 11 shows this stress-strain relationship, which assumes a conservative concrete compressive strength, $f_{c}{ }^{\prime}=$ 20.7 MPa (3,000 psi). It can be observed that all generated stresses lie within the suggested linear limit ( $L L)$ of $40 \%$ of $f_{c}$ ' (shown as black dashed line) (fib 2010). The ranges of generated stresses

364 for "very soft” and "very strong” impact forces spanning the means +/- two standard deviations taken from data shown in Fig. 9 (b) are provided for reference. To conclude, effects due to material

366 nonlinearity can be assumed to have a negligible effect on the proposed nonlinearity parameter, 367 NVI. 


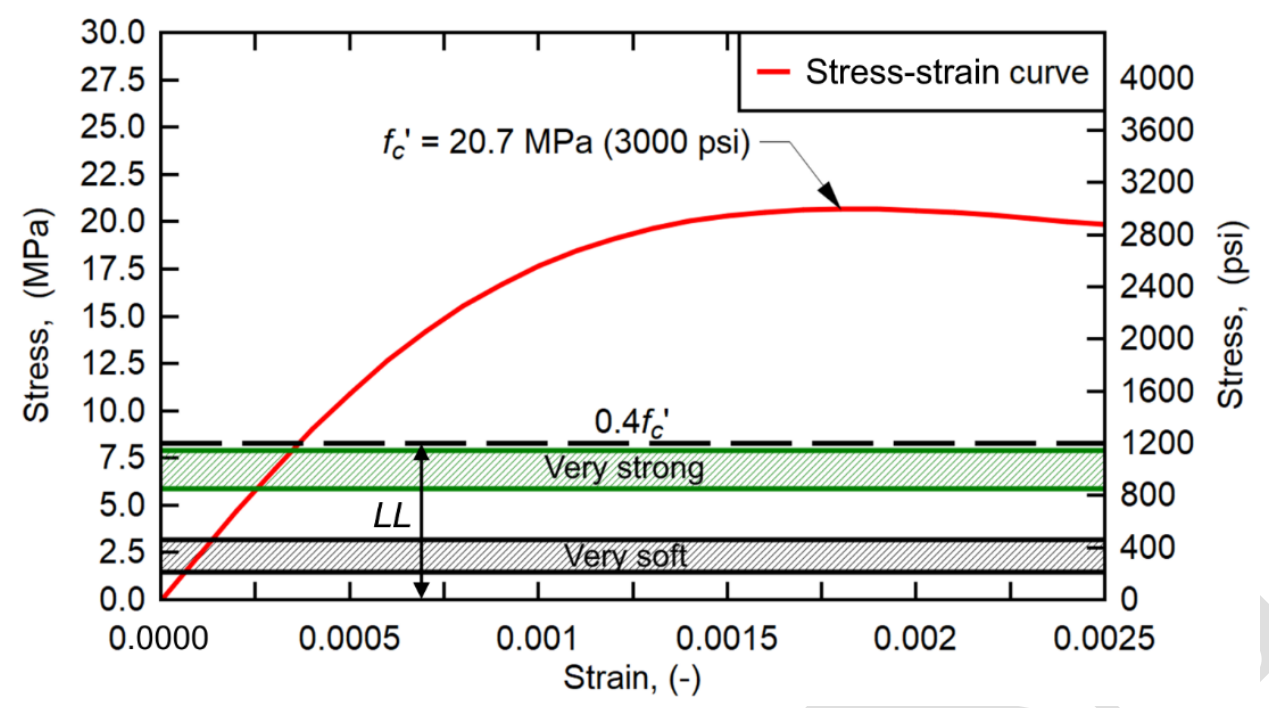

368 Strain, (-)

369 Fig. 11. Theoretical Stress-Strain relationship and actual generated stress ranges due to "very soft” (grey area) and "very strong” (green area) impact forces (ranges span mean +/- two

371 standard deviations). The black dashed horizonal line represents the suggested linear limit ( $L L)$.

372

373 Cracks resulting from concrete degradation is the second factor leading to nonlinearity, and of

374 interest to this study. Cracks open and close during vibrations, leading to a complex dynamic

375 response when the crack boundaries interact, which has been referred to as crack breathing

376 (Giannini, Casini et al. 2014). Although the cracks are initially small and distributed, they may

377 grow and coalesce to eventually form a localized macro crack such as a shallow delamination in a

378 concrete bridge deck. As demonstrated in Section 3, the proposed NVI should theoretically be able

379 to detect this type of damage. While a delamination is distinctly different from distributed micro

380 cracks, the crack breathing model still applies; in fact, it can be hypothesized that it is much more

381 pronounced for this case. 
382 To conclude, since material nonlinearity is deemed negligible, only cracking-related degradation

383 should affect the NVI. Furthermore, it is assumed that the stress-strain relationship does not have

384 a notable effect on detectability of concrete degradation such as a delamination.

\section{Results and Discussion}

\subsection{Verification of Results from Individual Test Points}

388 As has been reported, the crack boundary interaction of a delamination can cause nonlinear 389 vibrations due to the effects of the crack breathing phenomenon (Giannini, Casini et al. 2014). In 390 this section, results from six test points on Deck \#2 were selected and are discussed in detail to 391 evaluate the proposed test method. The six test points were divided into three groups (A, B, and 392 C) according to the observed results from the proposed method, available cores, and visual 393 inspection (see Fig. 9 (a) for test point locations). Each group consists of two test points (see Table 394 1). Note that "very soft" serves as the reference case for the three other impact forces, namely 395 "soft", "strong", and "very strong". The level of nonlinearity of the tested locations, which is 396 represented by the NVI, was computed over a frequency range of $f_{1}=225$ to $f_{2}=500 \mathrm{~Hz}$. The lower 397 limit, $f_{1}$ of this subjective range was chosen to exclude low-frequency noise caused by traffic, 398 wind, etc. The upper limit, $f_{2}$ was selected to minimize the effect of nonlinearity introduced by the 399 used accelerometer. In a previous study the authors used the same instrumentation and found this 400 type of nonlinear vibration response to start at approximately $600 \mathrm{~Hz}$ (Hafiz and Schumacher 401 2019). Therefore, the upper limit was conservatively set at $500 \mathrm{~Hz}$. 
Table 1. Six selected test point coordinates and their NVI; "very soft" = reference case.

\begin{tabular}{|c|c|c|c|c|c|c|}
\hline Group & $\begin{array}{c}\text { Location } \\
\text { [see Fig. } 9 \\
\text { (a) }]\end{array}$ & $\begin{array}{c}x \\
{[\mathrm{~m}(\mathrm{ft})]}\end{array}$ & $\begin{array}{c}y \\
{[\mathrm{~m}(\mathrm{ft})]}\end{array}$ & \multicolumn{3}{|c|}{ NVI (-) } \\
\cline { 5 - 7 } & & & Soft & Strong & $\begin{array}{c}\text { Very } \\
\text { strong }\end{array}$ \\
\hline \multirow{2}{*}{ A } & A1 & $0.305(1.00)$ & $8.84(29.0)$ & 0.99 & 0.98 & 0.98 \\
\cline { 2 - 7 } & A2 & $5.79(19.0)$ & $6.40(21.0)$ & 0.98 & 0.98 & 0.97 \\
\hline \multirow{2}{*}{ B } & B1 & $5.79(19.0)$ & $2.13(7.00)$ & 0.63 & 0.49 & 0.44 \\
\cline { 2 - 7 } & B2 & $5.18(17.0)$ & $0.305(1.00)$ & 0.96 & 0.91 & 0.98 \\
\hline \multirow{2}{*}{ C } & C1 & $8.84(29.0)$ & $3.96(13.0)$ & 0.38 & 0.25 & 0.05 \\
\cline { 2 - 7 } & C2 & $5.18(17.0)$ & $3.96(13.0)$ & 0.89 & 0.88 & 0.86 \\
\hline
\end{tabular}

404 Group A represents two test points that were not found to have any form of degradation by visual 405 inspection. Fig. 2 shows the FRF for test point A1, as well as the peak impact forces. Recall from 406 the discussion in Section 3, although the impact force was more than doubled, this only had a very 407 minor effect on the FRF, which implies the system is linear. Fig. 3 shows the $R^{2}$-frequency 408 relationship for test point A1, which is close to 1, indicating near linear behavior. Similarly, the $409 R^{2}$-frequency relationship of test point A2 is also not significantly affected by the increase of the 410 impact force, as can be observed in Fig. 12 (a). Since any structure will demonstrate a certain level 411 of nonlinearity, 3\% can be interpreted as the uncertainty in the NVI value for non-degraded 412 concrete in this study. The concrete core taken near test point A2 is further proof that this location 413 is in healthy condition, i.e., not showing any delamination, as can be seen in Fig. 13 (a). In 414 conclusion, areas on the bridge deck that do not show signs of nonlinear vibration behavior can be 415 considered healthy, i.e., free of degradation or delaminations, which supports the basic idea behind 416 our proposed method. 

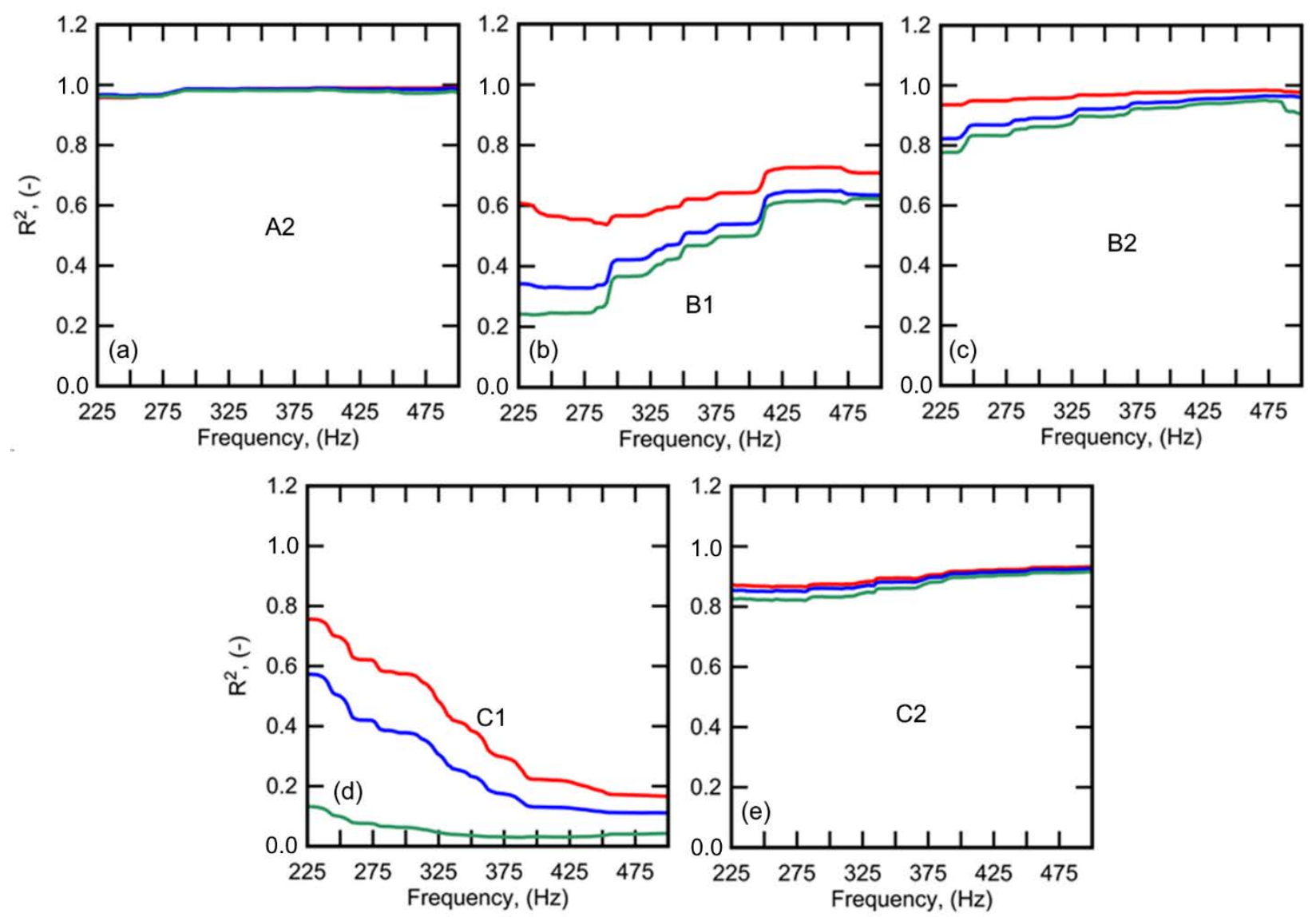

418 Fig. 12. $R^{2}$ - frequency relationships for test point A2 (a), B1 (b), B2 (c), C1 (d), and C2 (e).

419 Locations of these test points are shown in Fig. 9(a). Photos of extracted cores corresponding to

420 (a) and (b) are shown in Fig. 13. Note that the $R^{2}$-frequency relationships for test point A1 is 

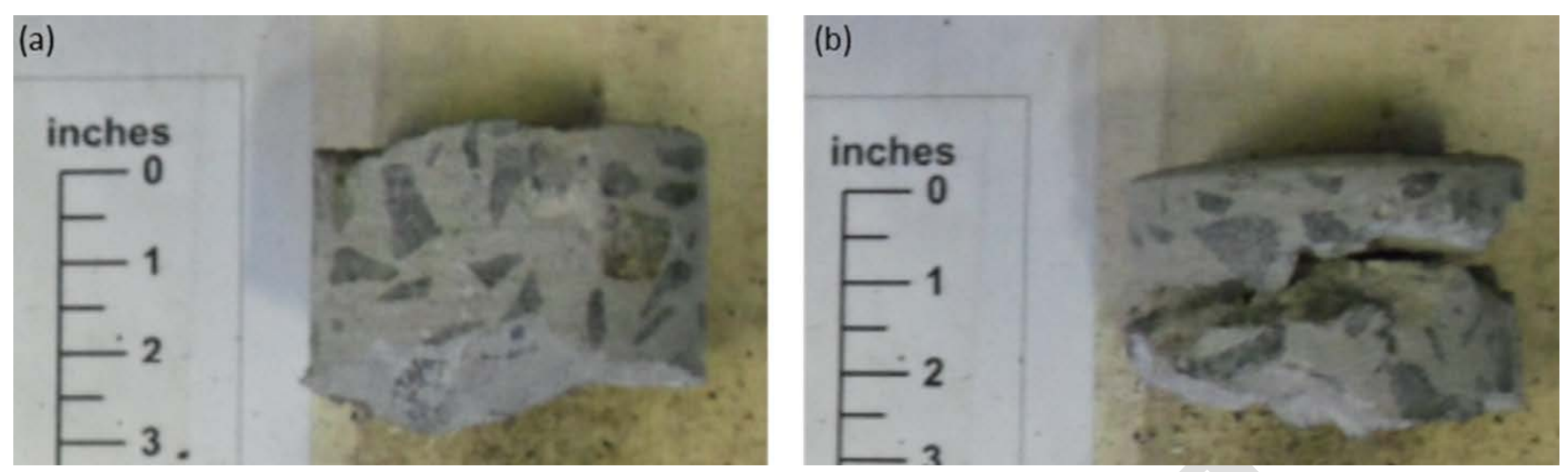

Fig. 13. Photos of extracted concrete cores: (a) Core 1 (near A2) and (b) Core 2 (near B1).

425 Group B represents two test points that were marked having delaminations by means of chain drag.

426 The $R^{2}$ - frequency relationships for the Group B test points are presented in Figs. 12 (b) and (c). It

427 can be observed that the responses are significantly affected with increasing impact force, leading

428 to low $R^{2}$ functions. Additionally, along with an increase in the amplitude of the impact force, the 429 change in the $R^{2}$ - frequency relationship increases, resulting in a decrease in the $N V I$ value, as 430 shown in Table 1. This response is distinctly different from the one found in Group A. These 431 results also match the core taken near test point B1, which shows a horizontal crack at a depth of 432 approximately 25 mm (1 in) [see Fig. 13 (b)]. In conclusion, the Group B results further confirm 433 that our proposed method can detect delaminations. The NVI values for test point B2 are not as 434 low as for B1, which is where visual inspection found a small, delaminated area [see Fig. 9 (a)].

436 Group C represents two test locations that exhibited nonlinear vibration behavior, but where the 437 visual inspection did not find any degradation or delaminations. The two associated test points 438 exhibited strong nonlinear vibration behavior, as shown in their FRFs [see Figs. 12 (d) and (e)]. 439 Unfortunately, no cores were available for the Group C test locations. However, the NVI values 
440 could be compared with the depth of the removed concrete after hydro-blasting was performed,

441 which is discussed in more detail in Section 6.2. The depth of removed concrete for these locations

442 was approximately $40 \mathrm{~mm}$ (1.6 in) for C1 and C2, which can be considered relatively high.

443 Assuming that hydro-jetting removes more depth when the concrete is degraded, i.e., having

444 distributed micro cracks, the hypothesis that the NVI method can detect degradation is also

445 supported.

447 Since only two cores were available for the entire deck, a comparison between the NVI results and

448 the depth of removed concrete was the only way to evaluate the proposed method for all 270 test 449 points, which is discussed in the subsequent section.

451 5.2. Comparison of Results with Removed Concrete

452 Fig. 14 shows contour plots of (a) NVI values and (b) depth of removed concrete by hydro-blasting

453 across the entire Deck \#2. NVI values were computed between the "very soft" (= reference) and

454 "very strong" impact forces. Both NVI results and depth of removed concrete agree in that there is

455 a large degraded or delaminated area along the centerline of the deck as highlighted by the black

456 dashed box. Additionally, both figures show that the area highlighted by the gray dashed boxes

457 are in good condition. On the other hand, the NVI method missed a literal hole in the deck found

458 after hydro-blasting had been completed, as highlighted by the red dashed box. This, however,

459 makes sense, since a hole is simply the case of material missing in some area, which is not the

460 same as an area of degraded concrete. Also, several low NVI values, e.g., around $x=5.49$ to 6.71

$461 \mathrm{~m}$ (18 to $22 \mathrm{ft}$ ) and $y=0.91$ to $2.13 \mathrm{~m}$ (3 to $7 \mathrm{ft}$ ), which would point to degradation or delamination,

462 are visible that could not be associated with a high depth of removed concrete. Note that the NVI 
463 value for test point B1 was consistent with the nearby concrete core that was found to have a

464 delamination, as is discussed in Section 5.1. The discrepancy away from this test point highlights

465 the need for additional work to better understand other factors not yet considered. 

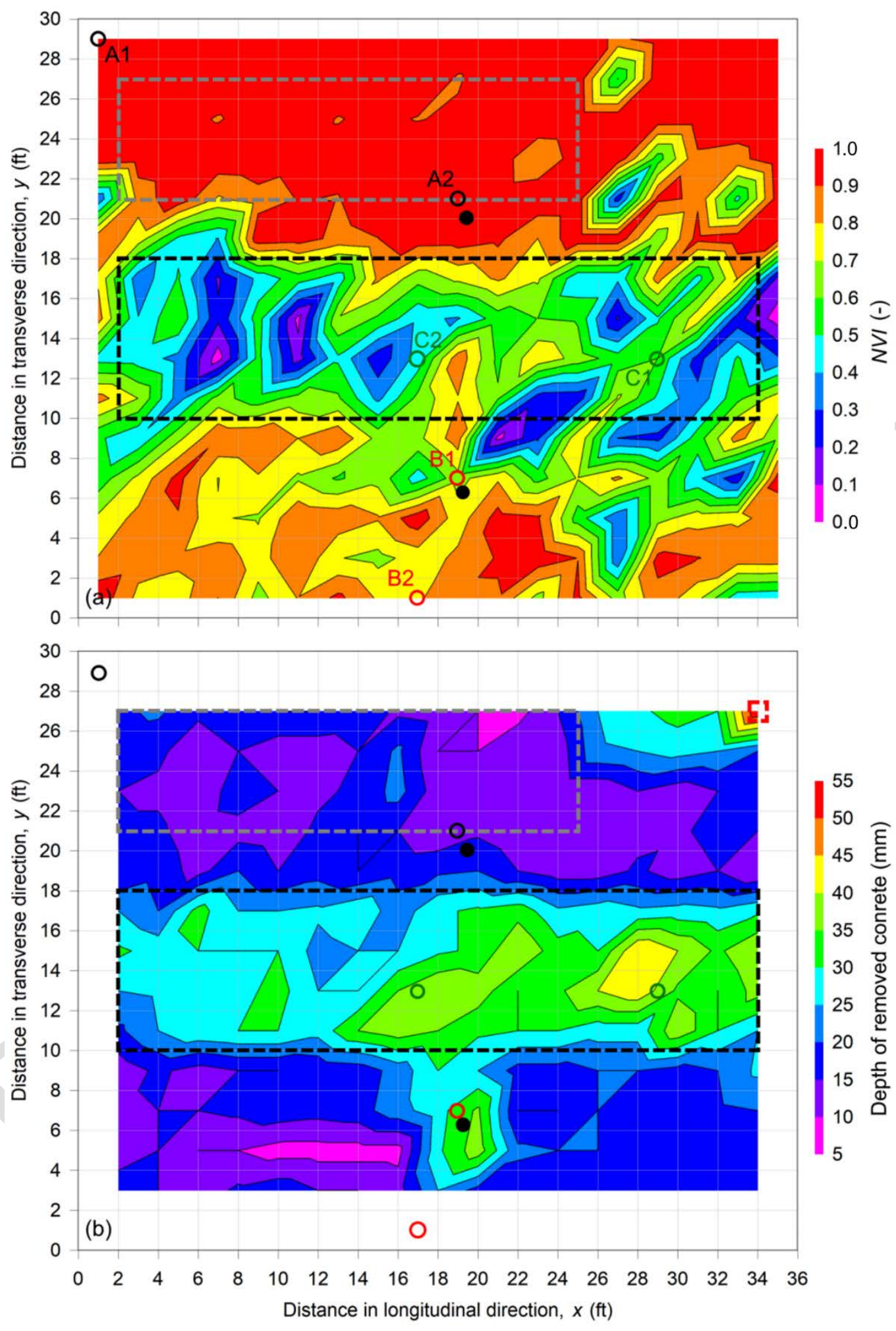

467 Fig. 14. Contour plots for (a) NVI values and (b) depth of removed concrete for Deck \#2. Circles 468 depict select test points discussed in more detail in Section 5.1. Unit conversion: $1 \mathrm{ft}=0.305 \mathrm{~m}$. 
469 Fig. 15 shows a correlation plot between NVI values and depth of removed concrete. The data 470 behind this plot were generated by interpolating the two datasets shown Fig. 14 over a range $x=$ 4710.610 to $10.4 \mathrm{~m}$ ( 2 to $34 \mathrm{ft}$ ) and $y=0.914$ to $8.23 \mathrm{~m}$ ( 3 to $27 \mathrm{ft}$ ) using the generate mesh function 472 with planar interpolation available in DPlot (Hyde 2014). Linear least-squares regression was 473 performed on these data to determine the mean prediction curve (red dash-dotted line) and 95\% 474 prediction limits (blue dotted lines). While a linear relationship with statistical significance at the $47595 \%$ confidence level exists, the correlation coefficient, $R=-0.532$ is low and considerable scatter 476 is present. As such, this relationship should only be interpreted as an indication of an overall trend. 477 Orange and blue dots correspond to data points from within the grey and black dashed boxes, 478 respectively, shown in Fig. 14, and the red dot corresponds to the location of the hole discussed 479 earlier [at $x=10.4 \mathrm{~m}(34 \mathrm{ft}), y=8.23 \mathrm{~m}(27 \mathrm{ft}$ ]). While it can be concluded that the NVI cannot be 480 directly used to predict the amount of removed concrete during hydro-blasting, Fig. 15 nonetheless 481 indicates that our proposed method is not only capable of detecting the onset of delaminations but 482 may also be sensitive to distributed damage. Note that a data analysis following conventional IR 483 parameters (ASTM 2016) did not reveal any of these issues (Clem 2013). 


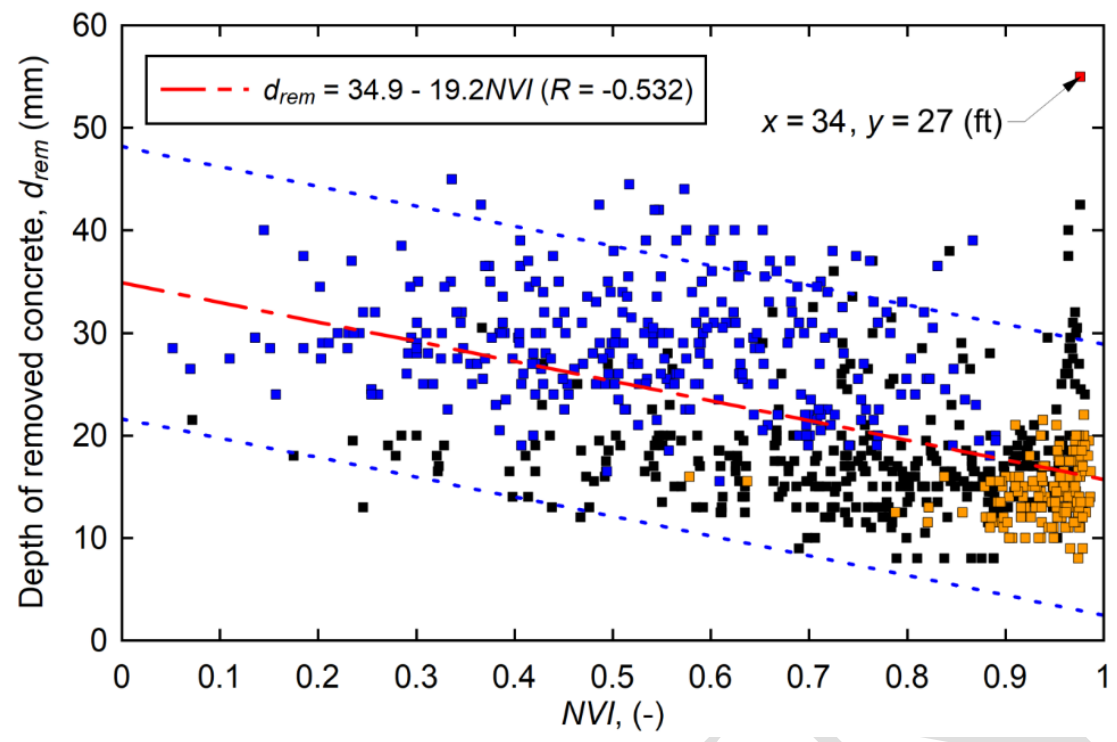

Fig. 15. NVI - Depth of removed concrete vs. NVI correlation plot. Orange and blue dots correspond to data points from within the grey and black dashed boxes, respectively, shown in Fig. 14. The red dash-dotted line and blue dotted lines represent the mean prediction curve and 95\% prediction limits, respectively. Unit conversion: $1 \mathrm{ft}=0.305 \mathrm{~m}$.

\section{Summary and Conclusions}

491 The presented results demonstrate the potential for our proposed nonlinear vibration index (NVI)

492 method to detect degradation and delamination in reinforced concrete bridge decks. The NVI

493 method is based on the concept of deviation from linearity, which is determined by computing the

494 frequency response functions (FRFs) for a set of increasing impact forces applied to a specific test

495 point and comparing them via correlation coefficients. The hypothesis is that if the FRFs remain

496 constant and change, this can be associated with healthy and degraded or damaged areas,

497 respectively. A numerical study using a finite element (FE) model demonstrated that nonlinear

498 behavior was indeed exhibited for a deck with a delamination when subject to increasing impact 
499 forces. The proposed method was then evaluated using data from an in-service bridge deck. The

500 equipment is the same as is used for impulse response (IR) tests on concrete plates. The results of

501 the field study support the proposed hypothesis. A comparison between NVI results and visual

502 inspection results, extracted concrete cores for six test locations, as well as depth of removed

503 concrete from hydro-blasting was performed. The final observations and conclusions are as

504 follows:

505 - NVI results were able to distinguish healthy areas in the bridge deck with ones that had 506 degradation or delaminations. Additionally, NVI results were in excellent agreement with $507 \quad$ visual inspection and core test results.

508 - A strong match was found between the results of the NVI method and visual inspection and

509 cores for detecting areas that could potentially have degradation or delamination.

510 - A qualitative comparison between NVI values and depth of removed concrete showed

511 acceptable agreement in terms of areas of degradation or delaminations.

512 - An overall trend was found between NVI values and depth of removed concrete. While notable

513 scatter exists, a linear regression revealed a trend consistent with the proposed hypothesis. Note

514 that the mean prediction equation found through linear least-squares regression should not be

515 used to predict depth of removed concrete.

516

517 It should be noted that the proposed method, at this point, cannot distinguish between type of 518 damage. Additional research is required before predictions with respect to type of damage and 519 depth of removed concrete can be made reliably. Future work includes additional modeling and 520 laboratory work to establish firm relationships as well as define the limitations of the method. For 
521 example, additional scenarios should be studied where crack depth, crack extent, applied force,

522 etc. are varied, to ensure the method works under many possible configurations in the field.

\section{7. Acknowledgments}

525 The authors thank The Higher Committee for Education Development in Iraq for supporting the 526 first author. Test equipment was made available by the Department of Civil and Environmental

527 Engineering at the University of Delaware. The data analyzed in this article were collected as part 528 of a research project sponsored by the Delaware Department of Transportation. We thank Dr.

529 Lassaad Mhamdi, Daniel J. Clem, Tayler C. Wennick, and Kaitlyn N. Gisonda for assisting with 530 data collection. Access to the bridge as well as traffic management during testing was provided by 531 Dr. Kaz Tabrizi and Dr. Manuel Celaya from Advanced Infrastructure Designs and Greg Bitsko 532 from Cherry, Weber \& Associates, and are greatly appreciated.

\section{References}

535 Abdelkhalek, S. and T. Zayed (2020). "Comprehensive Inspection System for Concrete Bridge Deck Application: Current Situation and Future Needs." ASCE Journal of Constructed Facilities 34(5): 03120001.

Arndt, R. W., T. Schumacher, D. Algernon and S.-H. Kee (2011). "Strategies for maintenance of highway bridges in the U.S. - with the support of non-destructive testing and structural health monitoring." Bautechnik 88(11): 793-804.

ASTM (2016). C1740: Standard Practice for Evaluating the Condition of Concrete Plates Using the Impulse-Response Method. West Conshohocken, PA, ASTM International. 
Bien, J., J. Krzyzanowski, W. Poprawski, W. Skoczynski and J. Szymkowski (2002). Experimental study of bridge structure dynamic characteristics using periodic excitation. International Conference on Noise and Vibration Engineering. Leuven, Belgium. II: 555-562.

Carreira, D. J. and K.-H. Chu (1985). "Stress-Strain Relationship for Plain Concrete in Compression." ACI Journal Proceedings 82(6): 797-804.

Celaya, M., T. Schumacher, K. Tabrizi, G. Bitsko and P. Shokouhi (2014). Field Verification of Non-destructive Testing Technologies for Condition Assessment of Concrete Bridge Decks:

A Case Study. NDE/NDT for Structural Materials Technology for Highway \& Bridges. Washington, D.C., ASNT.

Centurion, S. (2020). STATGRAPHICS. The Plains, VA, Statgraphics Technologies, Inc.

Clem, D. J. (2013). Evaluation of impulse response \& ground-penetrating radar as a means of nondestructive testing of concrete bridge decks. M.S. Thesis. Newark, DE, University of Delaware.

Clem, D. J., J. S. Popovics, T. Schumacher, T. Oh, S. Ham and D. Wu (2013). Understanding the impulse response method applied to concrete bridge decks. Review of Progress in Quantitative Nondestructive Evaluation. Denver, CO, AIP Conference Proceedings. 1511: 1333-1340.

Davis, A. G. (2003). "The nondestructive impulse response test in North America: 1985-2001." NDT \& E International 36(4): 185-193.

Davis, A. G. and C. Germann Petersen (2003). Nondestructive Evaluation of Prestressed Concrete Bridges using Impulse Response. Non-Destructive Testing in Civil Engineering 2003. Berlin, Germany, NDT.net.

Davis, A. G. and S. A. Robertson (1975). "Economic Pile Testing." Ground Engineering 8(3): 4043.

572 Garrett, S. (2019). "Nondestructive Assessment of Bridge Decks." Materials Evaluation 77(4). 
Giannini, O., P. Casini and F. Vestroni (2014). "Nonlinear Harmonic Identification of Cracks in Structures." Dynamics of Civil Structures 4: 207-217.

Gucunski, N., A. Imani, F. Romero, S. Nazarian, Y. Deren, H. Wiggenhauser, P. Shokouhi, A.

Hafiz, A. and T. Schumacher (2019). "Effects of Elastic Supports and Flexural Cracking on Low and High Order Modal Properties of a Reinforced Concrete Girder." Engineering Structures 178: $573-585$.

Hyde, D. (2014). DPlot. Vicksburg, MS, HydeSoft Computing LLC.

Idriss, M., A. El Mahi and R. El Guerjouma (2015). "Characterization of Sandwich Beams with Debonding by Linear and Nonlinear Vibration Method." Composite Structures 120: 200-207.

Kee, S.-H. and N. Gucunski (2016). "Interpretation of Flexural Vibration Modes from ImpactEcho Testing." ASCE Journal of Infrastructure Systems 22(3): 04016009.

Kee, S.-H., T. Oh, J. S. Popovics and R. W. Arndt (2012). "Nondestructive Bridge Deck Testing with Air-Coupled Impact-Echo and Infrared Thermography." ASCE Journal of Bridge Engineering 17(6): 928-939.

Kerschen, G., K. Worden, A. F. Vakakis and J.-C. Golinval (2006). "Past, Present and Future of Nonlinear System Identification in Structural Dynamics." Mechanical Systems and Signal Processing 20(3): 505-592.

Lin, R. (1990). Identification of the Dynamic Characteristics of Nonlinear Structures. PhD, University of London.

Lin, S., H. Azari, D. Meng and S. Shams (2021). Nondestructive Evaluation of Concrete Bridge Decks with Overlays. Washington, D.C., FHWA Turner-Fairbank Highway Research Center. Liu, C.-J., M. D. Todd, Z.-L. Zheng and Y.-Y. Wu (2017). "A Nondestructive Method for the Pretension Detection in Membrane Structures Based on Nonlinear Vibration Response to Impact." Structural Health Monitoring 17(1): 67-79.

Mathworks (2020). MATLAB. Natick, MA, Mathworks.

NCHRP (2004). Concrete Bridge Deck Performance - A Synthesis of Highway Practice. NCHRP Synthesis 333. Washington, D.C., Transportation Research Board.

Noel, J. P. and G. Kerschen (2017). "Nonlinear System Identification in Structural Dynamics: 10 More Years of Progress." Mechanical Systems and Signal Processing 83: 2-35. 
604

605

606

Sajid, S. and L. Chouinard (2019). "Inpulse response test for condition assessment of concrete: a review." Construction and Building Materials 211: 317-328.

Salawu, O. S. and C. Williams (1995). "Bridge Assessment Using Forced-Vibration Testing." ASCE Journal of Structural Engineering 121(2): 161-173.

Samman, M. M. and M. Biswas (1994). "Vibration Testing for Nondestructive Evaluation of Bridges. I: Theory." ASCE Journal of Structural Engineering 120(1): 269-289.

Samman, M. M. and M. Biswas (1994). "Vibration Testing for Nondestructive Evaluation of Bridges. II: Results." ASCE Journal of Structural Engineering 120(1): 290-306.

Sansalone, M. J. and W. B. Streett (1997). Impact-Echo - Nondestructive Evaluation of Concrete and Masonry. Ithaca, NY, Bullbrier Press.

Scherr, J. F. and C. Grosse (2021). "Delamination detection on a concrete bridge deck using impact echo scanning." Structural Concrete 22(2): 806-812.

Scott, M., A. Rezaizadeh, A. Delahaza, C. G. Santos, M. Moore, B. Graybeal and G. Washer (2003). "A Comparison of Nondestructive Evaluation Methods for Bridge Deck Assessment." NDT \& E International 36(4): 245-255.

Shokouhi, P., J. Wolf and H. Wiggenhauser (2014). "Detection of Delamination in Concrete Bridge Decks by Joint Amplitude and Phase Analysis of Ultrasonic Array Measurements." ASCE Journal of Bridge Engineering 19(3): 04013005.

Sun, H., J. Zhu and S. Ham (2018). "Automated Acoustic Scanning System for Delamination Detection in Concrete Bridge Decks." ASCE Journal of Bridge Engineering 23(6): 04018027. Systemes, D. (2012). ABAQUS 6.12.

Underwood, S. S., J. J. Meyer and D. E. Adams (2015). "Damage Localization in Composite Structures Using Nonlinear Vibration Response Properties." Journal of Vibration and Acoustics 137(3): 031015.

Zhang, G., R. S. Harichandran and P. Ramuhalli (2012). "Automatic Delamination Detection of Concrete Bridge Decks Using Impact Signals." ASCE Journal of Bridge Engineering 17(6): 951-954.

Zhao, X. Y., Z.-Q. Lang, G. Park, C. R. Farrar, M. D. Todd, Z. Mao and K. Worden (2015). "A New Transmissibility Analysis Method for Detection and Location of Damage via Nonlinear Features in MDOF Structural Systems." IEEE/ASME Transactions on Mechatronics 20(4): 1933-1947. 
635 Zhou, H. F., Y. Q. Ni and J. M. Ko (2011). "Eliminating Temperature Effect in Vibration-Based 636 Structural Damage Detection." ASCE Journal of Engineering Mechanics 137(12): 785-796.

637 Zhou, Z., L. D. Wegner and B. F. Sparling (2007). "Vibration-Based Detection of Small-Scale 638 Damage on a Bridge Deck." ASCE Journal of Structural Engineering 133(9): 1257-1267. 